\title{
Parameters of Thyroid Function Throughout and After Pregnancy in an lodine-Deficient Population
}

\author{
Maria José Costeira, ${ }^{1,2}$ Pedro Oliveira, ${ }^{1,3}$ Susana Ares, ${ }^{4}$ Susana Roque, \\ Gabriella Morreale de Escobar, ${ }^{5,6}$ and Joana Almeida Palha ${ }^{1}$
}

Background: The thyroid hormone milieu is of crucial importance for the developing fetus. Pregnancy induces physiological changes in thyroid homeostasis that are influenced by the iodine status. However, longitudinal studies addressing thyroid function during pregnancy and after delivery are still lacking in mild-to-moderate iodine-deficient populations. Here we characterize the serum parameters of thyroid function throughout pregnancy, and until 1 year after delivery, in a population of pregnant women whom we have previously reported to be iodine deficient (median urinary iodine levels below $75 \mu \mathrm{g} / \mathrm{L}$ ).

Methods: One hundred eighteen pregnant women were studied. Clinical data were recorded and serum was collected. Serum total and free thyroxine $\left(\mathrm{T}_{4}\right)$ and triiodothyronine $\left(\mathrm{T}_{3}\right)$, thyroid-stimulating hormone, thyroxinebinding globulin, and thyroglobulin were measured.

Results: Mean total $\mathrm{T}_{4}$ ranged from 159 at the start of gestation to $127 \mathrm{nmol} / \mathrm{L}$ at 1 year after delivery, free $\mathrm{T}_{4}$ from 14.2 to $17.8 \mathrm{pmol} / \mathrm{L}$, total $\mathrm{T}_{3}$ from 2.4 to $2.1 \mathrm{nmol} / \mathrm{L}$, free $\mathrm{T}_{3}$ from $6.7 \mathrm{pmol} / \mathrm{L}$ to $6.4 \mathrm{pmol} / \mathrm{L}$, thyroidstimulating hormone from 1.2 to $1.4 \mathrm{mIU} / \mathrm{L}, \mathrm{T}_{4}$-binding globulin from 62.0 to $26.9 \mathrm{mg} / \mathrm{L}$, and thyroglobulin from 11 to $10 \mu \mathrm{g} / \mathrm{L}$.

Conclusion: The pregnant women in this study had an absence of the usual free $\mathrm{T}_{4}$ spike and a smaller than expected increment in total $\mathrm{T}_{4}$, described during pregnancy in iodine-sufficient populations. A greater number of women had subclinical hypothyroidism compared with iodine-sufficient populations. This hormonal profile, most likely due to iodine insufficiency, may result in inadequate thyroid hormone supply to the developing fetus. We conclude that care should be taken when reviewing the results of thyroid hormone tests in iodineinsufficient populations and when no gestation-specific reference values have been established. In addition, we recommend iodine supplementation in our population and populations with similar iodine status, particularly during pregnancy and lactation.

\section{Introduction}

$\mathbf{P}$ REGNANCY IS ASSOCIATED with profound modifications in the regulation of thyroid function and economy. These changes are the result of various factors: increase of thyroxinebinding globulin (TBG) due to elevated estrogen, elevated levels of human chorionic gonadotropin that has thyroidstimulating hormone (TSH)-like activity, increased renal losses of iodine due to increased glomerular filtration rate, modifications in the peripheral metabolism of maternal thy- roid hormones, and iodine transfer to the placenta $(1,2)$. The physiologic adaptations that will optimize the maternal status for fetal development require adequate iodine intake. Iodine is essential for the synthesis of the thyroid hormones needed for the proper development of the central nervous system $(1,2)$. Therefore, interpretation of thyroid tests during pregnancy should consider these physiologic changes and the iodine status of the population (2-4).

The fetus relies completely on maternal thyroid hormones until the onset of its own thyroid function at the end of the first

This work in part has been presented, in part, as an abstract in the Ninth Congress of the Portuguese Society of Endocrinology, Diabetes, and Metabolism, Lisbon, Portugal, 2008.

${ }^{1}$ Life and Health Sciences Research Institute (ICVS), School of Health Sciences, University of Minho, Braga, Portugal.

${ }^{2}$ Centro Hospital Alto Ave-EPE, Guimarães, Portugal.

${ }^{3}$ Department of Production and Systems Engineering, University of Minho, Braga, Portugal.

${ }^{4}$ Department of Neonatology, La Paz University Hospital, Madrid, Spain.

${ }^{5}$ Instituto de Investigaciones Biomédicas Alberto Sols, Universidad Autónoma de Madrid, Madrid, Spain.

${ }^{6}$ Consejo Superior de Investigaciones Cientificas, Madrid, Spain. 
trimester; the mother continues to supply thyroid hormones and iodine until birth, and iodine during lactation $(1,2,5)$. Although severe iodine deficiency has long been known to cause mental retardation, increasing evidence shows that maternal hypothyroidism and maternal euthyroid hypothyroxinemia are related to poorer psychomotor development of the newborn (5-8). Therefore, recommendations on iodine supplementation prior and throughout pregnancy and until the end of lactation have been made by investigators and clinicians (9). This is particularly relevant, considering that many developed and developing countries are still considered iodine insufficient $(9,10)$. Controversy exists, however, on whether to monitor thyroid function throughout pregnancy $(11,12)$. A joint statement from the American Association of Clinical Endocrinologists, American Thyroid Association, and the Endocrine Society defends "routine screening for subclinical thyroid dysfunction in adults, including pregnant women and those contemplating pregnancy" (13). The Endocrine Society in their comments on management of thyroid dysfunction during pregnancy and postpartum states that "universal screening of pregnant women for thyroid disease is not yet supported by adequate studies..." $(14,15)$. Finally, the American College of Obstetricians and Gynaecologists and the United States Preventive Services Task Force suggests "performing testing only in women with personal history or symptoms of thyroid disease and do not recommend universal testing" (16). A number of recent studies have been concerned with the cost-effectiveness of universal screening in pregnancy and the debate between "target high-risk case finding" and "universal screening" $(17,18)$. Many agree that for proper monitoring it is necessary to establish reference ranges for pregnancy and to choose the most informative thyroid hormone parameters $(3,4,12)$.

In the present study we characterized parameters of thyroid hormone function throughout pregnancy and after delivery in the same population of pregnant women we previously found to be mild-to-moderately iodine insufficient (19), as defined by the World Health Organization (WHO) criteria (20).

\section{Materials and Methods}

\section{Subjects}

The study was carried out at the hospital Centro Hospitalar do Alto Ave, EPE, Guimarães, Portugal, between January 2003 and December 2005. Guimarães is located $50 \mathrm{~km}$ from the sea, with both urban and rural populations, in a total of about 1.2 million inhabitants. One hundred forty consecutive pregnant women (without exclusion criteria, see below) entering the antenatal clinic were invited to perform thyroid function tests during and after pregnancy. Upon agreement, demographic and clinical details were collected, including age, gestational age, number of previous pregnancies, breastfeeding 3 months after delivery, and Graffar socioeconomic cultural state. A food-frequency questionnaire was used to ascertain the number of weekly fish meals (a relevant source of dietary iodine), the use of iodized salt or iodinecontaining multivitamin pills, and whether the eating regimen was vegetarian. Exclusion criteria were the use of drugs or iodinated antiseptics, previous diabetes, assisted medical reproduction, malformations of the fetus, autoimmune disorders, thyroidal and other endocrine dysfunctions, and heavy smoking (more than 10 cigarettes per day). Women with multiple pregnancies or with antithyroidal antibodies (antithyroglobulin [anti-Tg] and/or antiperoxidase [antiTPO]) were later excluded from the analysis. A total of 118 pregnant women thus remained in the study.

All women enrolled gave informed written consent and the study was approved by the research ethical committee of the Centro Hospitalar do Alto Ave. We have previously characterized this population for iodine by measuring urine and breast milk iodine levels (19).

\section{Thyroid function measures}

Blood was collected in each trimester of pregnancy (12 \pm 1 , $24 \pm 1$, and $32 \pm 1$ weeks), when admitted to the hospital in labor, and at 3 days, 3 months, and 1 year after delivery. Blood was centrifuged and serum was kept at $-80^{\circ} \mathrm{C}$ until use. The following serum parameters were measured: total thyroxine $\left(\mathrm{TT}_{4}\right)$, free $\mathrm{T}_{4}\left(\mathrm{FT}_{4}\right)$, total triiodothyronine $\left(\mathrm{TT}_{3}\right)$, free $\mathrm{T}_{3}\left(\mathrm{FT}_{3}\right)$, $\mathrm{TSH}, \mathrm{Tg}$, and anti-TPO and anti-Tg antibodies using the DYNOtest radioimmunoassay reagents from Brahms Diagnostica $\mathrm{GmbH}$ (Berlin, Germany): DYNOtest $\mathrm{FT}_{4}$ (SPART), DYNOtest $\mathrm{T}_{4}$, DYNOtest $\mathrm{T}_{3}$, DYNOtest TSH, DYNOtest TgS, DYNOtest anti-TPO, and DYNOtest anti-Tgn. Manufacturer's normal reference ranges were $\mathrm{TT}_{4} 58-154 \mathrm{nmol} / \mathrm{L}, \mathrm{FT}_{4} 10-$ $25 \mathrm{pmol} / \mathrm{L}, \mathrm{TT}_{3} 1.23-3.08 \mathrm{nmol} / \mathrm{L}, \mathrm{FT}_{3} 3.4-8.5 \mathrm{pmol} / \mathrm{L}, \mathrm{TSH}$ 0.3-4.0 mIU/L, Tg $<70 \mu \mathrm{g} / \mathrm{L}$, anti-TPO $<60 \mathrm{U} / \mathrm{mL}$, and anti$\mathrm{Tg}<60 \mathrm{U} / \mathrm{mL}$. For TBG the manufacturer provided a reference range for pregnancy of $16.4-64.4 \mathrm{mg} / \mathrm{L}$. Conversion units used were as follows: $\mathrm{FT}_{3}$ in $\mathrm{pmol} / \mathrm{L}=(\mathrm{pg} / \mathrm{mL}) / 0.651$; $\mathrm{FT}_{4}$ in $\mathrm{pmol} / \mathrm{L}=(\mathrm{pg} / \mathrm{mL}) / 0.777$.

Subclinical hypothyroidism was defined as a serum TSH concentration above the statistically defined upper limit of the reference range (percentile $[\mathrm{P}]$ 97.5) when serum $\mathrm{FT}_{4}$ concentration was within reference range, and overt hypothyroidism as serum $\mathrm{TSH}$ values $>\mathrm{P} 97.5$ and $\mathrm{FT}_{4}<\mathrm{P} 2.5$. Subclinical hyperthyroidism was defined as a serum TSH concentration below the statistically defined lower limit of the reference range $(\mathrm{P} 2.5)$ when serum $\mathrm{FT}_{4}$ concentration was within reference range, and overt hyperthyroidism as TSH values $<$ P2.5 and $\mathrm{FT}_{4}>\mathrm{P} 97.5$. Isolated hypothyroxinemia when $\mathrm{TT}_{4}$ or $\mathrm{FT}_{4}$ values $<\mathrm{P} 2.5$ and $\mathrm{TSH}$ was normal (8).

\section{Statistical analyses}

Considering that some variables exhibited a much skewed distribution (Tg and TSH), the median was used as the measure of central tendency together with the interquartile range and percentiles. Correlations between variables were done using the Pearson's correlation or Spearman's rank correlation tests.

The comparison of several analytes throughout trimesters was conducted using repeated measures. In some cases $\left(\mathrm{TT}_{3}\right.$, $\mathrm{TSH}, \mathrm{Tg}$ ), the log transformation was used so that the distributions were approximately normal. The assumption of sphericity was evaluated through the Mauchly's test, and when the test was significant, the degrees of freedom were corrected using the Greenhouse-Geisser estimate of sphericity. Pairwise comparisons were corrected with the Bonferroni method.

Statistical analyses were performed using the SPSS 15 software package (SPSS, Chicago, IL). Values were considered significant when $p<0.05$. All tests were two sided. 


\section{Results}

\section{Demographic data}

From the initial pool of 140 pregnant women, 15 were excluded for being positive for either anti-TPO or anti-Tg, 1 of these had a pregnancy loss, and 7 for multiple pregnancies (all twins). The remaining 118 women had a medium age of 29.9 years (standard deviation: 7.0) and were pregnant for an average of 2.3 times (standard deviation: 1.4 ), 55.9\% belonged to a medium-high socioeconomical status, and $51.4 \%$ ate fish less than three times a week.

There was no difference between the thyroid function of women with anti-TPO and anti-Tg antibodies (10.7\% of the study population) when compared with those without antibodies (data not shown).

\section{Thyroid function throughout pregnancy and after delivery}

Figure 1 represents the P10, P50, and P90 for all parameters measured in pregnant women in the first, second, and third trimesters, in the beginning of labor, and at 3 days, 3 months, and 1 year after delivery. It is expected that the values at 1 year after delivery represent the basal levels, because the effects of pregnancy should have disappeared $(2,11,21)$. Because of the absence of $\mathrm{FT}_{4}$ surge and of the small increment of $\mathrm{TT}_{4}$, percentiles of these hormones were skewed to lower ranges. The detailed numerical values (median and interquartile range) of the thyroid function are presented in Table 1.

$\mathrm{FT}_{4}$ levels during pregnancy were always lower than after delivery, whereas $\mathrm{TT}_{4}, \mathrm{TT}_{3}$, and $\mathrm{TBG}$ levels were higher during pregnancy than after delivery, although $\mathrm{TT}_{4}$ increased only $25 \%$ above the basal level compared with the expected $50 \%(1-3,21)$. The molar ratio $\mathrm{TT}_{3} / \mathrm{TT}_{4}$ remained steady (0.016-0.017) throughout pregnancy.

Statistical analysis revealed significant differences across trimesters, albeit the small changes in median values. $\mathrm{TT}_{4}$ values changed significantly between the first and the third trimesters, and the second and the third trimesters, whereas $\mathrm{FT}_{4}, \mathrm{FT}_{3}$, and $\mathrm{TSH}$ values changed significantly between all three trimesters (first and second, second and third, and first and third). TBG values changed significantly between the first and the second trimesters and between the first and the third trimesters, and Tg changed between the first and the third and between the second and the third trimesters.

\section{Thyroidal dysfunction}

In the first trimester of pregnancy two women had overt hyperthyroidism and one had overt hypothyroidism. The incidence of subclinical hypothyroidism changed according to different thresholds: if defined by TSH > P97.5 (3.99 mIU/L in this population) it was $1.7 \%$, but if the value of $2.5 \mathrm{mIU} / \mathrm{L}$ was considered it was $7.6 \%$. The same occurred with subclinical hyperthyroidism: $1.7 \%$ of the women had TSH values $<$ P2.5 $(0.08 \mathrm{mIU} / \mathrm{L}$ in this population) and $7.6 \%$ presented levels below the reference range provided by the manufacturer. It should be noted that during the first trimester of pregnancy, TSH levels are expected to decrease; therefore, a cutoff of $2.5 \mathrm{mIU} / \mathrm{L}$ may be still too high $(3,4)$. In that case, the percentage of pregnant women displaying signs of subclinical hypothyroidism may be higher in our population.
Isolated hypothyroxinemia defined as $\mathrm{TT}_{4}$ levels $<\mathrm{P} 2.5$ $(97.0 \mathrm{nmol} / \mathrm{L})$ was found in $1.7 \%$ of the pregnant women, but when the absolute value of $\mathrm{TT}_{4}<100 \mathrm{nmol} / \mathrm{L}$ suggested in the literature was used, this number increased to $2.6 \%$. There is no universal absolute value of $\mathrm{FT}_{4}$ to define hypothyroxinemia (its value is dependent on the method and on the trimester of gestation) $(3,4)$. It should be emphasized that these absolute reference values are for the nonpregnant population and that in the first trimester $\mathrm{TT}_{4}$ and $\mathrm{FT}_{4}$ are expected to increase while TSH is expected to decrease.

Table 2 shows the correlations between the various analytes studied. Of interest, the second trimester revealed fewer correlations than any other time point $\left(\mathrm{TT}_{4}\right.$ tended to correlate with $\mathrm{FT}_{4}, \mathrm{TT}_{3}$, and $\mathrm{FT}_{3} ; \mathrm{TT}_{3}$ correlated with $\mathrm{FT}_{3}$ ), and in the first trimester and 1 year after delivery there was a negative correlation between $\mathrm{TT}_{3}$ and $\mathrm{FT}_{4}$.

We also assessed correlations between thyroid function and demographic characteristics, and no major correlations were found (data not shown).

\section{Discussion}

To respond properly to the pregnancy's increased $T_{4}$ demand, several adaptations are triggered during pregnancy $(1,2,5)$. These should not pose a major problem to the thyroid status of the pregnant women, and consequently to the fetal development, in iodine-sufficient populations. The present study focused on pregnant women (singleton and negative for antithyroid antibodies) from a mild-to-moderate iodine-insufficient area (19), as defined by the criteria established by the WHO (20): median urinary iodine in the three trimesters of pregnancy and milk iodine concentrations of $<75 \mu \mathrm{g} / \mathrm{L}$ and $<100 \mu \mathrm{g} / \mathrm{L}$, respectively (19). Of note, this had an impact on the progeny of these women, because median neonatal urinary iodine was low (71 and $97 \mu \mathrm{g} / \mathrm{L}$ at 3 days and 3 months of age) (19). Here we have further extended the study to characterize serum parameters of thyroid function throughout pregnancy and up to 1 year after delivery, selecting from the initial pregnant population those singleton and negative for anti-TPO and anti-Tg antibodies. $\mathrm{TT}_{4}, \mathrm{TT}_{3}$, and $\mathrm{TBG}$ levels were higher during pregnancy than after delivery. However, the increase of $\mathrm{TT}_{4}$ in the first trimester was small $(25 \%)$, when compared with that expected $(50 \%)$ in iodine-sufficient populations $(1-3,21)$, and further decreased throughout pregnancy rather than remaining steady (21). The $\mathrm{FT}_{4}$ levels did not show the termed " $\mathrm{FT}_{4}$ first trimester surge" $(1-3,21)$, instead these were always lower than basal levels throughout pregnancy and lower than other reports in iodine-sufficient populations $(8,9)$. Of note, the peak of TSH before labor preceded that of $\mathrm{Tg}$ at 3 days after delivery, being exaggerated in those women with some thyroid insufficiency (those with TSH values in P90). In addition, if an absolute cutoff of $2.5 \mathrm{mIU} / \mathrm{L} \mathrm{TSH}$ is considered, $8 \%$ of women in the first trimester of pregnancy are subclinically hypothyroid $(3,22-$ 25). As TSH levels normally decreased in the first trimester of pregnancy, the TSH cutoff of $2.5 \mathrm{mIU} / \mathrm{L}$ defined for nonpregnant women may still be too high for pregnant women $(3,4)$ and, therefore, even more women in our pregnant population may display subclinical hypothyroidism. These observations are in accordance with the iodine insufficiency previously described in this population (19). 


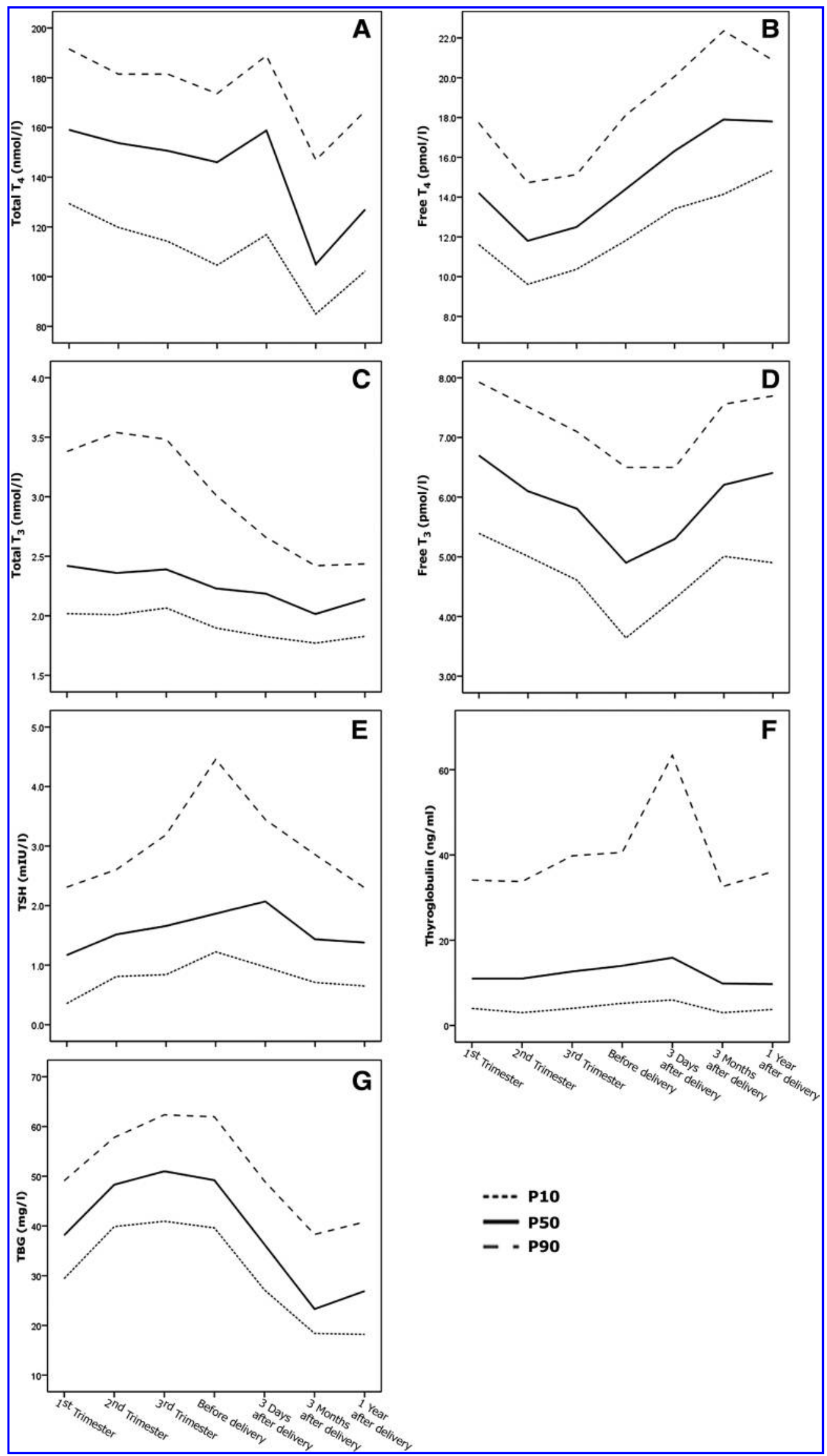

FIG. 1. Percentiles 10, 50, and 90 (P10, P50, P90) of thyroid analytes throughout and after pregnancy: $\mathrm{TT}_{4}(\mathbf{A}), \mathrm{FT}_{4}(\mathbf{B})$, $\mathrm{TT}_{3}$ $(\mathbf{C}), \mathrm{FT}_{3}(\mathrm{D}), \mathrm{TSH}(\mathrm{E})$, thyroglobulin $(\mathbf{F}), \mathrm{TBG}(\mathrm{G})$ in the first, second, and third trimesters, in the beginning of labor, and at 3 days, 3 months, and 1 year after delivery. $\mathrm{TT}_{4}$, total thyroxine; $\mathrm{FT}_{4}$, free $\mathrm{T}_{4} ; \mathrm{TT}_{3}$, total triiodothyronine; $\mathrm{FT}_{3}$, free $\mathrm{T}_{3} ; \mathrm{TSH}$, thyroid-stimulating hormone; TBG, thyroxine-binding globulin. 
Table 1. Measurements of Thyroid Function Throughout Pregnancy and at 1 Year After Delivery (Median, P25, and P75)

\begin{tabular}{|c|c|c|c|c|}
\hline Analyte & First trimester & Second trimester & Third trimester & 1 year after \\
\hline $\mathrm{TT}_{4}(\mathrm{nmol} / \mathrm{L})$ & $(n=117)$ & $(n=107)$ & $(n=105)$ & $(n=61)$ \\
\hline Median & 159.03 & 153.71 & 150.61 & 127.00 \\
\hline P25-75 & $144.36-172.56$ & $137.00-167.86$ & $128.12-166.15$ & $110.50-147.50$ \\
\hline $\mathrm{FT}_{4}(\mathrm{pmol} / \mathrm{L})$ & $(n=117)$ & $(n=107)$ & $(n=105)$ & $(n=61)$ \\
\hline Median & 14.21 & 11.80 & 12.50 & 17.80 \\
\hline P25-75 & $12.78-16.10$ & $10.46-13.66$ & $11.48-13.71$ & $16.31-19.31$ \\
\hline $\mathrm{TT}_{3}(\mathrm{nmol} / \mathrm{L})$ & $(n=118)$ & $(n=109)$ & $(n=105)$ & $(n=63)$ \\
\hline Median & 2.42 & 2.36 & 2.39 & 2.14 \\
\hline P25-75 & $2.20-2.86$ & $2.19-2.84$ & $2.25-2.75$ & $2.00-2.30$ \\
\hline $\mathrm{FT}_{3}(\mathrm{pmol} / \mathrm{L})$ & $(n=116)$ & $(n=96)$ & $(n=98)$ & $(n=59)$ \\
\hline Median & 6.70 & 6.10 & 5.81 & 6.41 \\
\hline P25-75 & $6.02-7.22$ & $5.50-6.79$ & $5.21-6.41$ & $5.50-7.10$ \\
\hline $\mathrm{TSH}(\mathrm{mIU} / \mathrm{L})$ & $(n=118)$ & $(n=104)$ & $(n=102)$ & $(n=59)$ \\
\hline Median & 1.17 & 1.52 & 1.66 & 1.38 \\
\hline P25-75 & $0.70-1.77$ & $1.17-2.08$ & $1.24-2.24$ & $0.94-1.75$ \\
\hline $\operatorname{Tg}(\mathrm{ng} / \mathrm{mL})$ & $(n=117)$ & $(n=105)$ & $(n=105)$ & $(n=61)$ \\
\hline Median & 11.00 & 11.00 & 12.65 & 9.70 \\
\hline P25-75 & $6.84-19.20$ & $5.50-16$ & $7.00-21.94$ & 5.95-20.35 \\
\hline TBG (mg/L) & $(n=112)$ & $(n=105)$ & $(n=104)$ & $(n=59)$ \\
\hline Median & 38.15 & 48.30 & 51.00 & 26.90 \\
\hline P25-75 & $33.13-43.45$ & $44.45-53.75$ & $45.43-56.68$ & $20.90-35.80$ \\
\hline
\end{tabular}

$\mathrm{TT}_{4}$, total thyroxine; $\mathrm{FT}_{4}$, free $\mathrm{T}_{4} ; \mathrm{TT}_{3}$, total triiodothyronine; $\mathrm{FT}_{3}$, free $\mathrm{T}_{3}$; $\mathrm{TSH}$, thyroid-stimulating hormone; $\mathrm{Tg}$, thyroglobulin; $\mathrm{TBG}$, thyroxine-binding globulin; $\mathrm{P}$, percentile.

Table 2. Correlation Coefficients (Spearman's $P$ ) For Thyroid Analytes in Pregnant Women

\begin{tabular}{|c|c|c|c|c|c|c|c|}
\hline & $\mathrm{TT}_{4}$ & $\mathrm{FT}_{4}$ & $\mathrm{TT}_{3}$ & $\mathrm{FT}_{3}$ & TSH & $T B G$ & $\mathrm{Tg}$ \\
\hline \multicolumn{8}{|c|}{ First trimester } \\
\hline \multicolumn{8}{|c|}{$\mathrm{TT}_{4}$} \\
\hline $\mathrm{FT}_{4}$ & $0.34^{\mathrm{a}}$ & 1 & & & & & \\
\hline $\mathrm{TT}_{3}$ & $0.31^{\mathrm{a}}$ & $-0.29^{a}$ & 1 & & & & \\
\hline FT3 & $0.23^{\mathrm{b}}$ & -0.10 & $0.43^{\mathrm{a}}$ & 1 & & & \\
\hline $\mathrm{TSH}$ & $-0.30^{\mathrm{a}}$ & $-0.23^{b}$ & -0.08 & -0.02 & 1 & & \\
\hline TBG & $0.29^{\mathrm{a}}$ & -0.02 & 0.04 & $0.26^{\mathrm{a}}$ & 0.00 & 1 & \\
\hline $\mathrm{Tg}$ & 0.07 & -0.02 & 0.05 & -0.10 & -0.09 & 0.01 & 1 \\
\hline \multicolumn{8}{|c|}{ Second trimester } \\
\hline $\mathrm{TT}_{4}$ & 1 & & & & & & \\
\hline $\mathrm{FT}_{4}$ & 0.05 & 1 & & & & & \\
\hline $\mathrm{TT}_{3}$ & $0.34^{\mathrm{a}}$ & 0.03 & 1 & & & & \\
\hline $\mathrm{FT}_{3}$ & 0.19 & -0.13 & 0.19 & 1 & & & \\
\hline TSH & -0.09 & -0.14 & -0.06 & 0.00 & 1 & & \\
\hline TBG & $0.36^{\mathrm{a}}$ & -0.16 & 0.13 & $0.40^{\mathrm{a}}$ & 0.09 & 1 & \\
\hline $\mathrm{Tg}$ & 0.06 & 0.07 & 0.04 & 0.07 & -0.07 & -0.02 & 1 \\
\hline \multicolumn{8}{|c|}{ Third trimester } \\
\hline $\mathrm{TT}_{4}$ & 1 & & & & & & \\
\hline $\mathrm{FT}_{4}$ & $0.27^{\mathrm{a}}$ & 1 & & & & & \\
\hline $\mathrm{TT}_{3}$ & $0.56^{\mathrm{a}}$ & $-0.20^{\mathrm{b}}$ & 1 & & & & \\
\hline $\mathrm{FT}_{3}$ & $0.44^{\mathrm{a}}$ & 0.00 & $0.61^{\mathrm{a}}$ & 1 & & & \\
\hline $\mathrm{TSH}$ & $-0.22^{b}$ & -0.07 & $-0.22^{b}$ & -0.03 & 1 & & \\
\hline TBG & $0.52^{\mathrm{a}}$ & -0.06 & $0.49^{\mathrm{a}}$ & $0.52^{\mathrm{a}}$ & -0.05 & 1 & \\
\hline $\mathrm{Tg}$ & 0.13 & -0.02 & -0.07 & -0.05 & -0.02 & 0.05 & 1 \\
\hline \multicolumn{8}{|c|}{1 year after delivery } \\
\hline $\mathrm{TT}_{4}$ & 1 & & & & & & \\
\hline $\mathrm{FT}_{4}$ & -0.15 & 1 & & & & & \\
\hline $\mathrm{TT}_{3}$ & $0.66^{\mathrm{a}}$ & $-0.47^{\mathrm{a}}$ & 1 & & & & \\
\hline $\mathrm{FT}_{3}$ & $0.62^{\mathrm{a}}$ & -0.21 & $0.70^{\mathrm{a}}$ & 1 & & & \\
\hline TSH & 0.04 & -0.16 & 0.09 & -0.04 & 1 & & \\
\hline TBG & $0.79^{a}$ & $-0.47^{\mathrm{a}}$ & $0.75^{\mathrm{a}}$ & $0.56^{\mathrm{a}}$ & 0.17 & 1 & \\
\hline $\operatorname{Tg}$ & 0.17 & 0.02 & 0.13 & 0.22 & 0.06 & 0.07 & 1 \\
\hline
\end{tabular}

${ }^{\mathrm{a}}$ Correlation is significant at the 0.01 level.

${ }^{\mathrm{b}}$ Correlation is significant at the 0.05 level. 
We chose to recruit women from a public hospital for this study because most women in Portugal attend the public health system. However, caution should be taken when extrapolating these results to the general population given the small size of the studied population, the recruitment of women from a single hospital and region of Portugal, and the fact that these women are iodine deficient.

We and other investigators have determined the parameters of thyroid function at various moments throughout pregnancy, both in populations considered iodine sufficient $(26,27)$ and insufficient $(1,2,14,28)$. Nevertheless, to the best of our knowledge, the present study is the first considering as basal levels of thyroid function those at 1 year after delivery, for the same women. In addition, it is correspondingly the most extensive analysis for women for whom information on urinary and milk iodine levels and thyroid gland volumes is available.

Iodine deficiency remains a problem worldwide (20). In fact, none of the women in our study reported consumption of iodinated salt. This problem is twofold: (i) several countries, including Portugal and other coastal countries, do not follow the WHO recommendation on the use of household iodized salt or iodine supplementation $(10,29)$ and, therefore, (ii) women are not knowledgeable of the importance of iodinated salt in their diet and if they are this is not necessarily widely available. Further, data about iodine sufficiency in pregnant women are scarce worldwide and many countries report urinary iodine values lower than the recommended $(19,29)$, as we also found in this study. The data presented here contributes to the discussion on whether thyroid function should be monitored before and/or throughout pregnancy, on which thyroid function parameter is most appropriate for such screening $(4,11-16,30)$, and on the need to establish a cutoff for identifying hypothyroxinemia/hypothyroidism in pregnant women that is distinct from the cutoff that defines normality in the general population (24). When considering hypothyroxinemia, our results confirm other findings $(5,7,8,25)$ in which, using the current reference range for TSH, measurement of TSH alone is not sufficient. Screening is, however, controversial, because scientific and clinical societies do not agree on whether the available data are sufficient to provide such recommendations (13-15). Although severe iodine insufficiency is well recognized as the second major cause of preventable mental retardation, after starvation $(1,5,10)$, an increasing body of evidence suggests that mild iodine insufficiency prevents children from fully achieving their intellectual potential $(5,7,8)$. Identification of hypothyroxinemia during pregnancy, particularly in the first trimester, when fetal thyroid hormones rely exclusively on the mother's, is important because it has been shown to result in poorer pregnancy outcome $(5,14)$, negatively impacting the psychomotor development and intelligence coefficient of the progeny $(1,5-8)$. For these reasons, the WHO and several investigators are recommending supplementation of iodine before and during pregnancy, as well as the screening of thyroid function before or in the beginning of pregnancy $(14,17,18)$. In conclusion, we recommend that a general policy on salt iodization and iodine supplementation during pregnancy and lactation be implemented, and that when no gestation-specific reference values are established, care should be taken when analyzing the results of thyroid hormone tests in iodine-insufficient populations.

\section{Acknowledgments}

The contributions of the authors were as follows: M.J.C., S.A., S.R., J.A.P., and G.M.E. planned and conducted the research, discussed the data, and drafted the manuscript. P.O. conducted the statistical analysis together with the other authors. J.A.P. is the principal investigator of the project that funded this research. This study was supported by the Portuguese Science Foundation (FCT)-European Fund of Regional Development (FEDER) grant POCTI_PSI_60948_ 2004 and by the Integrated Actions for Exchange of Scientists "Portugal-Spain E-84/2006."

\section{Disclosure Statement}

The authors declare that no competing financial interests exist.

\section{References}

1. Morreale Escobar G, Obregon MJ, Escobar del Rey F 2007 Iodine deficiency and brain development in the first half of pregnancy. Public Health Nutr 10:1554-1570.

2. Glinoer D 2007 Clinical and biological consequences of iodine deficiency during pregnancy. Endocr Dev 10:62-85.

3. Baloch Z, Carayon P, Conte-Devolx B, Demers LM, FeldtRasmussen U, Henry JF, LiVosli VA, Niccoli-Sire P, John R, Ruf J, Smyth PP, Spencer CA, Stockigt JR 2003 Guidelines Committee, National Academy of Clinical Biochemistry. Laboratory medicine practice guidelines. Laboratory support for the diagnosis and monitoring of thyroid disease. Thyroid 13:3-126.

4. Stricker RT, Echenard M, Eberhart R, Chevailler M-C, Perez V, Quinn FA, Stricker RN 2007 Evaluation of maternal thyroid function during pregnancy: the importance of using gestational age-specific reference intervals. Eur J Endocrinol 157:509-514.

5. Morreale de Escobar G, Obregón MJ, Escobar del Rey F 2000 Is neuropsychological development related to maternal hypothyroidism or to maternal hypothyroxinemia? I Clin Endocrinol Metab 85:3975-3987.

6. Haddow JE, Palomaki GE, Allan WC, Williams JR, Knight GJ, Gagnon J, O'Heir CE, Mitchell ML, Hermos RJ, Waisbren SE, Faix JD, Klein RZ 1999 Maternal thyroid deficiency during pregnancy and subsequent neuropsychological development of the child. N Engl J Med 341:549-555.

7. Berbel P, Mestre JL, Santamaría A. Palazón I, Franco A, Graells M, González-Torga A, de Escobar GM 2009 Delayed neurobehavioral development in children born to pregnant women with mild hypothyroxinemia during the first month of gestation: the importance of early iodine supplementation. Thyroid 19:511-519.

8. Pop VJ, Brouwers EP, Vader HL, Vulsma T, van Baar AL, de Vijlder JJ 2003 Maternal hypothyroxinemia during early pregnancy and subsequent child development: a 3-year follow-up study. Clin Endocrinol (Oxf) 59:282-288.

9. Andersson M, de Benoist B, Delange F, Zupan J $2007 \mathrm{WHO}$ Secretariat on behalf of the participants to the consultation. Prevention and control of iodine deficiency in pregnant and lactating women and in children less than 2-years-old: conclusions and recommendations of the Technical Consultation. Public Health Nutr 10:1606-1611.

10. Andersson M, de Benoist B, Darnton-Hill I, Delange F 2007 Iodine Deficiency in Europe: A Continuing Public Health Problem. World Health Organization, Geneva. 
11. Wier FA, Farley CL 2006 Clinical controversies in screening women for thyroid disorders during pregnancy. J Midwifery Womens Health 51:152-158.

12. Mandel SJ, Spencer C, Hollowell J 2005 Are detection and treatment of thyroid insufficiency in pregnant feasible? Thyroid 15:44-53.

13. Gharib H, Tuttle RM, Baskin HJ, Fish LH, Singer PA, McDermott MT 2005 Consensus statement: subclinical thyroid dysfunction: a joint statement on management from the American Association of Clinical Endocrinologists, the American Thyroid Association, and the Endocrine Society. J Clin Endocrinol Metab 90:581-585.

14. Abalovich M, Nobobuyuki A, Barbour LA, Cobin RH, De Groot LJ, Glinoer D, Mandel SJ, Stagnaro-Green Alex 2007 Management of thyroid dysfunction during pregnancy and postpartum: an Endocrine Society clinical practice guideline. J Clin Endocrinol Metab 92:S1-S47.

15. Surks MI, Ortiz E, Daniels GH, Sawin CT, Col NF, Cobin RH, Franklyn JA, Hershman JM, Burman KD, Denke MA, Gorman C, Cooper RS, Weissman NJ 2004 Subclinical thyroid disease: scientific review and guidelines for diagnosis and management. J Am Med Assoc 291:228-238.

16. American College of Obstetricians and Gynecologists 2002 Thyroid disease in pregnancy: practice bulletin no. 37. Int J Gynaecol Obstet 79:171-180.

17. Thung SF, Funai EF, Grobman WA 2009 The cost-effectiveness of universal screening in pregnancy for subclinical hypothyroidism. Am J Obstet Gynecol 200:267 e1-7.

18. Vaidya B, Anthony S, Bilous M, Shields B, Drury J, Hutchison S, Milous R 2007 Detection of thyroid dysfunction in early pregnancy: universal screening or target high-risk case finding? J Clin Endocrinol Metab 92:203-207.

19. Costeira MJ, Oliveira P, Ares S, de Escobar GM, Palha JA 2009 Iodine status of pregnant women and their progeny in the Minho region of Portugal. Thyroid 19:157-163.

20. World Health Organization 2007 Assessment of Iodine Deficiency Disorders and Monitoring Their Elimination. A Guide for Programme Managers, 3rd edition. World Health Organization, Geneva.

21. Soldin OP, Tractenberg RE, Hollowell JG, Jonklaas J, Janicic N, Soldin SJ 2004 Trimester-specific changes in maternal thyroid hormone, thyrotropin, and thyroglobulin concentrations during gestation: trends and associations across trimesters in iodine sufficiency. Thyroid 14:1084-1090.

22. Shan ZY, Chen YY, Teng WP, Yu XH, Li CY, Zhou WW, Gao B, Zhou JR, Ding B, Ma Y, Wu Y, Liu Q, Xu H, Liu W, Li J, Wang WW, Li YB, Fan CL, Wang H, Guo R, Zhang HM 2009 A study for maternal thyroid hormone deficiency during the first half of pregnancy in China. Eur J Clin Invest 39:37-42.
23. Hamilton TE, Davis S, Onstad L, Kopecky KJ 2008 Thyrotropin levels in a population with no clinical autoantibody, or ultrasonographic evidence of thyroid disease: implications for the diagnosis of subclinical hypothyroidism. J Clin Endocrinol Metab 93:1224-1230.

24. Waise A, Price HC 2009 The upper limit of the reference range for thyroid-stimulating hormone should not be confused with a cut-off to define subclinical hypothyroidism. Ann Clin Biochem 46:93-98.

25. Surks MI, Goswami G, Daniels GH 2005 The thyrotropin range should remain unchanged. I Clin Endocrinol Metab 90:5489-5496.

26. Gilbert RM, Hadlow NC, Walsh JP, Fletcher SJ, Brown SJ, Stuckey BG, Lim EM 2008 Assessment of thyroid function during pregnancy: first-trimester (weeks 9-13) reference intervals derived from Western Australian women. Med J Aust 189:250-253.

27. Kurioka H, Takahashi K, Miyazaki K 2005 Maternal thyroid function during pregnancy and puerperal period. Endocr J 52:587-591.

28. Moleti M, Lo Presti VP, Mattina F, Mancuso A, De Vivo A, Giorgianni G, Di Bella B, Trimarchi F, Vermiglio F 2009 Gestational thyroid function abnormalities in conditions of mild iodine deficiency: early screening versus continuous monitoring of maternal thyroid status. Eur J Endocrinol 160:611-617.

29. Hollowell JG, Haddow JE 2007 The prevalence of iodine deficiency in women of reproductive age in the United States of America. Public Health Nutr 10:1532-1539.

30. Lambert-Messerlian G, McClain M, Haddow JE, Palomakis GE, Canick JA, Cleary-Goldman J, Malone FD, Porter F, Nyberg DA, Bernstein P, D'Alton ME 2008 First- and second-trimester thyroid hormone reference data in pregnant women: a FaSTER (First- and Second-Trimester Evaluation of Risk for aneuploidy) research consortium study. Am J Obstet Gynecol 199:62.e1-6.

Address correspondence to: Joana A. Palha, Ph.D.

Life and Health Sciences Research Institute (ICVS) School of Health Sciences

University of Minho

Campus Gualtar

Braga 4710-057 Portugal

E-mail: japalha@ecsaude.uminho.pt 
